Pacific Journal of Mathematics

ON THE SUM OF A PRIME AND OF TWO POWERS OF TWO 


\title{
ON THE SUM OF A PRIME AND OF TWO POWERS OF TWO
}

\author{
ROGER CROCKER
}

It has been shown by different methods that there is an infinity of positive odd integers not representable as the sum of a prime and a (positive) power of 2, thus disproving a conjecture to the contrary which had been made in the nineteenth century. The question then arises as to whether or not all sufficiently large positive odd integers can be represented as the sum of a prime and of two positive powers of 2; that is, as $p+2^{a}+2^{b}$, where $a, b>0$ and $p$ is prime. (The corresponding question has been discussed for bases other than 2 but is really quite trivial.) Theorem $I$ gives a negative answer to this question.

Theorem I. There is an infinity of distinct, positive odd integers not representable as the sum of a prime and of two positive powers of 2 .

Notation. Throughout this paper, each $p_{i}$ represents an odd prime. All quantities are integers and usually positive integers. As usual, "prime" is understood to mean "positive prime".

The method used in [1] gives Lemma I and Lemma II, below. The method used in [4] a slight modification of [3] is then combined with Lemma II to show that there is an infinity of positive odd integers not the sum of a prime and a positive power of 2 nor the sum of a prime and of two distinct positive powers of 2 . Theorem I follows immediately.

First, to reproduce the counterexample in [4, p. 413] slightly generalized here, consider an "overlapping" congruence system (1) (i.e., given any positive integer, it will satisfy at least one of the equations of the system; such a system occurs below)

$$
x_{i} \equiv a_{i}\left(\bmod m_{i}\right), \quad 1 \leqq i \leqq h .
$$

Suppose that from this system, one can construct the following simultaneous congruence system

$$
t \equiv\left\{\begin{array}{l}
2^{a_{i}}\left(\bmod p_{i}\right), 1 \leqq i \leqq h, \text { where } 2^{m_{i}} \equiv 1\left(\bmod p_{i}\right) ; \\
c\left(\bmod p_{h+1}\right), \text { where } p_{h+1}=2^{p}-1, p \text { a prime, and } \\
\quad c \not \equiv p_{i}+2^{d}\left(\bmod p_{h+1}\right) \text { for } 0 \leqq d \leqq p-1,1 \leqq i \leqq h ; \\
1(\bmod 2)
\end{array}\right.
$$

with all moduli $p_{i}, 1 \leqq i \leqq h+1$, distinct. (The $m_{i}$ need not be 
distinct and $p$ may be any prime, so long as all $p_{i}$ are distinct.) As shown by the method used in [4, p. 413], none of these odd integers is the sum of a prime and a power of 2 , so that the counterexample is valid. Finally, in reference to the supposition just above, for the actual numerical choice of (1) one must show the existence of distinct $p_{i}$ and of $c$ satisfying the above conditions; this will be done later for the choice of (1) made in this paper.

Now one arrives at

Lemma I. ${ }^{1}$ For every $n \geqq 3,2^{2^{n}}-1$ cannot be expressed as the sum of a prime and of two distinct positive powers of 2 .

Proof. Taking $a>b$ (which results in no loss of generality), consider $2^{2^{n}}-1-2^{a}-2^{b}=2^{2^{n}}-1-2^{b}\left(2^{a-b}+1\right)$ where $a, b<2^{n}$. Since $a-b<2^{n}$, it follows that for each $a-b$,

$2^{2^{r}}+1 \mid 2^{2^{n}}-1-2^{b}\left(2^{a-b}+1\right)$ for some $r<n(r$ being the largest power of 2 contained in $a-b)$. But since $2^{2^{n}}-1-2^{2^{n}-1}-2^{2^{n}-2}=$ $2^{2^{n-2}-1}>2^{2^{2 n-1}}+1$ for $n \geqq 3$, it follows that $2^{2^{n}}-1-2^{a}-2^{b}>2^{2^{r}}+1$. The lemma follows.

The result in Lemma I may be generalized very considerably to give

LEMMA II. ${ }^{2}$ For $n \geqq 3$ and $w \equiv 1 \quad(\bmod 16)$, consider $w \prod_{i=0}^{n-1} B_{i} \leqq 2^{2^{n}}-1$, where $B_{i} \mid 2^{2^{i}}+1$ and $B_{i}>1$ (though not necessarily prime or $\left.<2^{2^{i}}+1\right)$. Then $w \prod_{i=0}^{n-1} B_{i}\left(\leqq 2^{2^{n}}-1\right)$ cannot be expressad as the sum of a prime and of two positive distinct powers of 2 .

Proof. If $n=3,4$ or 5 , Lemma I is immediately applicable. Suppose $n \geqq 6$. Consider

$$
w \prod_{i=0}^{n-1} B_{i}-2^{a}-2^{b}=w \prod_{i=0}^{n-1} B_{i}-2^{b}\left(2^{a-b}+1\right)>0
$$

1 This Lemma was communicated to me by A. Schinzel after he had read [1], and also appears in [4, p. 413] where some acknowledgment is made of [1]. I arrived at Lemma I independently, however but did not publish it, since by itself it is quite incomplete. It might be added that, contrary to the impression given in [4 p. 414], Lemma $I$ is a trivial generalization of [1] using exactly the same method; this can easily be seen by comparing the proof in [1] with the above proof of Lemma I.

216 is far from the only possible modulus for $w$; any power of two $>16$ would be suitable. For example, 64 could be used; $w \equiv 1(\bmod 64), w \equiv 3(\bmod 64)$, or many other residue classes $(\bmod 64)$ could then be chosen, with only obvious and trivial changes in the subsequent proofs. If $w \equiv 3(\bmod 64)$ is chosen, the integers satisfying Theorem $I \equiv 1(\bmod 4)$. Incidentally, it occurred to me at first that it might be possible to "combine" Lemma I with the method in [3]. I then realized that some generalization of Lemma I would be necessary. My search led to Lemma II, which I then was able to "combine" with the method of [4]). 
where (without loss of generality) $a>b$; then $a, b<2^{n}$ and so $a-b<2^{n}$. Now for each $a-b, B_{r} \mid w \prod_{i=0}^{n-1} B_{i}-2^{b}\left(2^{a-b}+1\right)$ for some $r<n$, remembering that $B_{r}\left|2^{2 r}+1\right| 2^{a-b}+1$ for some $r<n$.

Now suppose $w \prod_{i=0}^{n-1} B_{i}-2^{a}-2^{b}=B_{r}$; then $w \prod_{i=0}^{n-1} B_{i}=2^{a}+2^{b}+B_{r}$. Now $\prod_{i=0}^{n-1} B_{i}=\prod_{i=0}^{4} B_{i} \prod_{i=5}^{n-1} B_{i} \equiv-1(\bmod 16)\left(\right.$ remembering that $B_{i} \equiv 1$ $\left(\bmod 2^{i+1}\right)$ or for $\left.i \geqq 5, B_{i} \equiv 1(\bmod 16)\right)$. Since $w \equiv 1(\bmod 16)$, it follows that $w \prod_{i=0}^{n-1} B_{i} \equiv-1(\bmod 16)$. Now with $r<n$, one has $w \prod_{i=0}^{n-1} B_{i}>B_{0} B_{1} B_{r}=15 B_{r}$ so that $w \prod_{i=0}^{n-1} B_{i}-B_{r}>14 B_{r} \geqq 42$ (since $\left.B_{r} \geqq 3\right)$; thus $2^{a}+2^{b} \geqq 42$ and since $a>b$, one must have $a>3$. Therefore $2^{a} \equiv 0(\bmod 16)$. But since $b \geqq 1, r \geqq 0$, one has $2^{b}$ congruent $(\bmod 16)$ to $0,2,4$ or 8 and $B_{r}$ congruent $(\bmod 16)$ to 1,3 or 5. Hence $2^{a}+2^{b}+B_{r} \not \equiv-1(\bmod 16)$; therefore $w \prod_{i=0}^{n-1} B_{i} \neq 2^{a}+2^{b}+B_{r}$. Thus $w \prod_{i=0}^{n-1} B_{i}-2^{a}-2^{b} \neq B_{r}$. The lemma follows.

Proof of Theorem I. Take $2^{2^{n}}-1 / G_{k}$ for some chosen fixed $k$, where $n>k, G_{k} \mid 2^{2^{k}}+1(k=10$ will actually be chosen later), and $1<G_{k}<2^{2^{k}}+1$. Now assume that one can choose an overlapping congruence system [(1), above] such that in the corresponding simultaneous congruence system [(2), above] one can have

$$
\left(p_{i}, 2^{2^{n}}-1\right)=1 \text { for any } p_{i} \text { and } n
$$

and also

$$
16 \prod_{i=1}^{h+1} p_{i}<G_{k} \text {, say }\left(16 \prod_{i=1}^{h+1} p_{i}\right) v<G_{k}<(v+1)\left(16 \prod_{i=1}^{h+1} p_{i}\right)
$$

for some fixed $v \geqq 1$.

Consider the system (2) having these properties, together with the additional simultaneous ${ }^{3}$ conditions (3)

$$
\begin{aligned}
t & \equiv 0\left(\bmod \frac{2^{2^{n}}-1}{G_{k}}\right) \\
t & \equiv-1(\bmod 16) \\
t & \leqq 2^{2^{n}}-1 ;
\end{aligned}
$$

choose any $n(>k)$. Call this enlarged simultaneous system $S_{n}$.

Now by the Chinese Remainder Theorem, $S_{n}$ is satisfied by any integer $t$ (and only those integers) such that

$$
t \equiv q_{n}\left(\bmod 16 \frac{2^{2^{n}}-1}{G_{k}} \prod_{i=1}^{h+1} p_{i}\right), \quad t \leqq 2^{2^{n}}-1
$$

where one may consider that $0<q_{n}<16\left(2^{2^{n}}-1 / G_{k}\right) \prod_{i=1}^{h+1} p_{i}$ and $q_{n}$, itself satisfying $S_{n}$, is obviously fixed for the chosen $n$ (but from (3)

${ }^{3}$ The condition $t \equiv-1(\bmod 16)$ absorbs, of course, that in $(2), t \equiv 1(\bmod 2)$. 
depends on the choice of $\left.n ; q_{n} \neq 0\right)$. Clearly, there are $v(\geqq 1)$ or $v+1$ positive integers satisfying this congruence and $\leqq 2^{2^{n}}-1$, that is, satisfying the conditions in $S_{n}$. Now from (3), each of these $(v$ or $v+1)$ integers satisfying the conditions in $S_{n}$ satisfies Lemma 2 . For let $B_{i}$ in Lemma 2 be $2^{2^{i}}+1$ here except when $i=k$, in which case let $B_{k}=2^{2^{k}}+1 / G_{k}$ (the $B_{i}$ satisfy the conditions required of them in the hypothesis of Lemma 2). Then $\prod_{i=0}^{n-1} B_{i}=2^{2^{n}}-1 / G_{k}$, so that from the first two conditions in (3), one has $t=w \prod_{i=0}^{n-1} B_{i} \equiv-1$ $(\bmod 16)$, where since $\prod_{i=0}^{n-1} B_{i} \equiv-1(\bmod 16)$, one has $w \equiv 1(\bmod 16)$. From the remaining condition in (3), $t \leqq 2^{2^{n}}-1$ so that $t=w \prod_{i=0}^{n-1} B_{i} \leqq 2^{2^{n}}-1$. Hence positive integers satisfying the conditions in $S_{n}$ satisfy the hypothesis of Lemma 2. Thus each of these $(v$ or $v+1)$ positive integers is not the sum of a prime and of two distinct positive powers of 2 . However each of these integers satisfies the system (2) and therefore is not the sum of a prime and a power of 2 ( $\mathrm{and}^{4}$ thus of a prime and of two identical powers of 2). Hence each of these integers satisfies (the desired property in) Theorem I. Now for $n+1(>k+1)$, each of the $(v$ or $v+1)$ positive integers satisfying $\left(S_{n+1}\right.$ and hence) Theorem $\mathrm{I}$ is divisible by $2^{2^{n}}+1$ (using $n+1$ in place of $n$ in (3)) and hence $\geqq 2^{2^{n}}+1$; for $n$, each of the integers $<2^{2^{n}}+1$. Thus the integers, satisfying Theorem I, which one obtains for integer $n$ are less than those obtained for the successive integer $n+1$. Since any $n(>k)$ may be chosen, Theorem I follows. Finally, choose $k=10, G_{k}=2^{2^{10}}+1 / 2^{12} \cdot 11131+1$, and $(1)$ to be $0(\bmod 3) \quad 0(\bmod 5) \quad 1(\bmod 9) \quad 1(\bmod 10) \quad 8(\bmod 12) \quad 8(\bmod 15)$ $4(\bmod 18) \quad 7(\bmod 20) \quad 5(\bmod 24) \quad 29(\bmod 30) \quad 2(\bmod 36) \quad 14(\bmod 36)$ 17( $\bmod 40) \quad 34(\bmod 45) \quad 43(\bmod 45) \quad 13(\bmod 48) \quad 37(\bmod 48) \quad 16(\bmod 60)$ 19(mod 60) $26(\bmod 72) \quad 62(\bmod 72) \quad 52(\bmod 90) \quad 37(\bmod 120) \quad 49(\bmod 144)$ 121 $(\bmod 144) \quad 103(\bmod 180) \quad 106(\bmod 180) \quad 229(\bmod 360)$.

(1) can be shown to be an overlapping congruence system by a very straightforward (though lengthy) numerical ${ }^{5}$ method - namely by writing all these congruences $(\bmod 720), 720$ being the L. C. M. of the $m_{i}$ 's chosen here, and then checking that one obtains a complete residue system $\bmod 720$. (For each congruence $\left(\bmod m_{i}\right)$ one obtains, of course, $720 / m_{i}$ congruences $(\bmod 720)$ which take the form $a_{i}+f m_{i}$ $\left.(\bmod 720), 0 \leqq f<720 / m_{i}\right)$.

Taking $p_{h+1}=2^{13}-1$ (for an appropriate $c$ ), it will now be shown

4 Actually, not being the sum of a prime and a positive power of 2 implies not being the sum of a prime and of two identical positive powers of 2 but is really slightly stronger (since 2 itself is a power of 2 but not the sum of two identical positive powers of 2 ).

5 Actually there is a relatively short way of showing this result related to a short cut I used originally to construct this system. However I hope to make this a topic of another paper. 
that one can in fact construct a system (2) such that the conditions stated above for the $p_{i}$ in system (2) are satisfied. For it is well known that for any positive integer $e \neq 6$, there is at least one prime, say $p^{\prime}$, such that 2 belongs to $e\left(\bmod p^{\prime}\right)$. Hence for each distinct ${ }^{6}$ $m_{i}$ in the numerical choice for (1), there exists a $p_{i}$ such that 2 belongs to $m_{i}\left(\bmod p_{i}\right)$; (this can also be shown numerically); these $p_{i}$ are of course distinct. For each nondistinct $m_{i}$ occurring in the above numerical choice for (1), the existence of a distinct $p_{i}$ such that 2 belongs to $m_{i}\left(\bmod p_{i}\right)$ has in fact been shown for general purposes numerically [2]. Now since $m_{i}=2^{g_{i}} k^{\prime}$ where $k^{\prime}$ is odd and $>1$ in the numerical choice for (1), $m_{i} \nmid 2^{n}$ (since $k^{\prime} \nmid 2^{n}$ ). But 2 belongs to $m_{i}\left(\bmod p_{i}\right)$; hence $2^{2^{n}} \not \equiv 1\left(\bmod p_{i}\right)$ for otherwise $m_{i}$ would divide $2^{n}$. Thus $\left(p_{i}, 2^{2^{n}}-1\right)=1$. Also $13 \nmid 2^{n}$; since 2 belongs to $13\left(\bmod p_{h+1}\right), 2^{2^{n}} \not \equiv 1\left(\bmod p_{h+1}\right)$. Thus $\left(p_{h+1}=2^{13}-1,2^{2^{n}}-1\right)=1$. Also $13 \nmid m_{i}$ here; again $\left(p_{h+1}, p_{i}\right)=1$ or $p_{h+1} \neq p_{i}, 1 \leqq i \leqq h$. Finally by simple numerical calculation and estimation,

$$
16 \prod_{i=1}^{h+1} p_{i}<2^{434}<2^{998}<G_{k} ;
$$

$v$ thus exists and in fact is seen to be very large here. It remains to show the existence of $c$ satisfying the required condition in system (2). There are $2^{13}-1$ possible distinct residues of $2^{13}-1\left(=p_{h+1}\right)$; there are also 13 distinct residues of $2^{d}\left(\bmod 2^{13}-1\right)$ and at most 28 $(=h)$ distinct residues $\left(\bmod 2^{13}-1\right)$ of the $p_{i}$ 's (not counting $p_{h+1}$ here), and thus there are at most $13(28)$ distinct residues of $p_{i}+2^{d}$ $\left(\bmod 2^{13}-1\right)$. Since $13(28)<2^{13}-1$, the existence of $c$ follows. (There are, in fact, at least $2^{13}-1-13(28)=7827$ possible distinct choices for $c$ ).

\section{REFERENCES}

1. R. Crocker, A theorem concerning prime numbers, Math. Magazine 34 (1960/61), 316 and 344.

2. L. E. Dickson, History of the Theory of Numbers, New York, 1952.

3. P. Erdös, On a problem concerning congruence systems, Mat. Lapok 3 (1952), 122128.

4. W. Sierpinski, Elementary Theory of Numbers, Warszawa, 1964.

Received September 3, 1969.

John Carroll University

${ }^{6}$ By a distinct $m_{i}$ in the system is meant an $m_{i} \neq m_{j}$, if $i \neq j$. 



\title{
PACIFIC JOURNAL OF MATHEMATICS
}

\author{
EDITORS
}

H. SAMELSON

Stanford University

Stanford, California 94305

C. R. Новву

University of Washington

Seattle, Washington 98105
J. DUGUNDJI

Department of Mathematics

University of Southern California

Los Angeles, California 90007

RICHARD ARENS

University of California

Los Angeles, California 90024

\section{ASSOCIATE EDITORS}

E. F. BECKENBACH

B. H. NeUManN

F. WOLF

K. YosHidA

\section{SUPPORTING INSTITUTIONS}

UNIVERSITY OF BRITISH COLUMBIA CALIFORNIA INSTITUTE OF TECHNOLOGY UNIVERSITY OF CALIFORNIA MONTANA STATE UNIVERSITY UNIVERSITY OF NEVADA NEW MEXICO STATE UNIVERSITY OREGON STATE UNIVERSITY UNIVERSITY OF OREGON OSAKA UNIVERSITY UNIVERSITY OF SOUTHERN CALIFORNIA
STANFORD UNIVERSITY UNIVERSITY OF TOKYO UNIVERSITY OF UTAH WASHINGTON STATE UNIVERSITY UNIVERSITY OF WASHINGTON

AMERICAN MATHEMATICAL SOCIETY CHEVRON RESEARCH CORPORATION TRW SYSTEMS

NAVAL WEAPONS CENTER 


\section{Pacific Journal of Mathematics}

\section{Vol. 36, No. $1 \quad$ November, 1971}

Norman Larrabee Alling, Analytic and harmonic obstruction on

nonorientable Klein surfaces ............................ 1

Shimshon A. Amitsur, Embeddings in matrix rings .............. 21

William Louis Armacost, The Frobenius reciprocity theorem and essentially bounded induced representations ....................... 31

Kenneth Paul Baclawski and Kenneth Kapp, Topisms and induced

non-associative systems ............................ 45

George M. Bergman, The index of a group in a semigroup ............ 55

Simeon M. Berman, Excursions above high levels for stationary Gaussian

processes....................................... 63

Peter Southcott Bullen, A criterion for $n$-convexity .............. 81

W. Homer Carlisle, III, Residual finiteness of finitely generated commutative

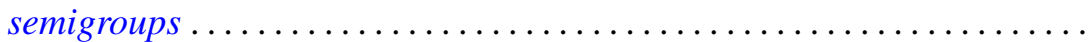

Roger Clement Crocker, On the sum of a prime and of two powers of

two ............................................ 103

David Eisenbud and Phillip Alan Griffith, The structure of serial rings . . . 109

Timothy V. Fossum, Characters and orthogonality in Frobenius

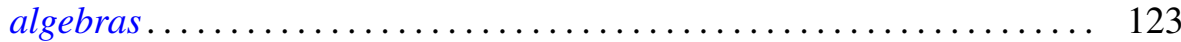

Hugh Gordon, Rings of functions determined by zero-sets . .......... 133

William Ray Hare, Jr. and John Willis Kenelly, Characterizations of Radon partitions...

Philip Hartman, On third order, nonlinear, singular boundary value

problems

David Michael Henry, Conditions for countable bases in spaces of

countable and point-countable type ..

James R. Holub, Hilbertian operators and reflexive tensor products ...

Robert P. Kaufman, Lacunary series and probability ..... . .

195

Erwin Kreyszig, On Bergman operators for partial differential equations in

two variables ................................

Chin-pi Lu, Local rings with noetherian filtrations . .

Louis Edward Narens, A nonstandard proof of the Jordan curve theorem...

S. P. Philipp, Victor Lenard Shapiro and William Hall Sills, The Abel summability of conjugate multiple Fourier-Stieltjes integrals. .

Joseph Earl Valentine and Stanley G. Wayment, Wilson angles in linear normed spaces

Hoyt D. Warner, Finite primes in simple algebras ...

Horst Günter Zimmer, An elementary proof of the Riemann hypothesis for an elliptic curve over a finite field... 